\title{
Investigation of Wind Energy Resource on the Basis of Weibull and Rayleigh Models in North Eastern and Western, Nigeria
}

\author{
Abdullahi Ahmed, Bashir Isyaku Kunya \\ Department of Mechanical Engineering, Kano University of Science and Technology, Wudil, Nigeria
}

Email address:

abdula2k2@yahoo.com (A. Ahmed)

\section{To cite this article:}

Abdullahi Ahmed, Bashir Isyaku Kunya. Investigation of Wind Energy Resource on the Basis of Weibull and Rayleigh Models in North Eastern and Western, Nigeria. American Journal of Aerospace Engineering. Vol. 6, No. 1, 2019, pp. 27-32. doi: 10.11648/j.ajae.20190601.15

Received: July 31, 2019; Accepted: August 28, 2019; Published: September 16, 2019

\begin{abstract}
This study is aimed to investigate wind energy resource on the basis of Weibull and Rayleigh models in north eastern (Bauchi and Maiduguri) and western (Kano and Sokoto) Nigeria, seventeen years (2000-2016) monthly wind speed data were collected from Nigeria meteorological station, Abuja at 10m height. The probability distribution function (pdf) of wind speed is very important tool needed in wind energy resource investigation, since wind power is proportional to the cube of wind speed. The Weibull parameters shape $(k)$ and scale $(c)$ for the four locations were determined and the values obtained for shape factors in Bauchi and Maiduguri range from 6.91 to 7.21 and Sokoto and Kano range from 9.27 to 10.68, while scale factors is in the range of 3.46 to 7.24 and 9.32 to 11.24 , respectively. The Weibull model was found to be better fit than the Rayleigh model in analyzing the wind speed data. The north western part of Nigeria was found to have higher wind power density as compared to the north eastern part of the country.
\end{abstract}

Keywords: Wind Power Density, Weibull Distribution, Rayleigh Distribution, Wind Speed Distribution

\section{Introduction}

Wind energy is one of the most significant and rapidly developing renewable energy sources all over the world because of its cheapest forms of energy available today. Recent technological developments, fossil fuel usage, environmental effects and continuous increase in the conventional energy resources has rendered wind energy costs to economically attractive levels and consequently, wind energy farms are being considered as alternative energy source in many enterprises [1]. The beneficial characteristics of wind power include cleaner and safer source of energy and inexhaustible fuel which generates electricity without releasing any harmful pollutants or gases as by products [2].

Wind energy is an efficient renewable energy, because it does not involve the use of any fossil fuels or non-renewable sources of energy like natural gas, coal or oil. It is green energy because it causes no carbon emissions therefore creating less pollution [3].

The problem being faced is that some of the wind turbines have failed completely or performed below expectation especially in developing countries because the installed wind turbine system do not match up with the site in which machines are been installed [4].

The wind speed distribution is of great importance for the assessment of wind energy potential and the performance of wind energy conversion system [5]. Various parameters of the wind are to be known, including the mean wind speed, directional data, seasonal and annual variation with heights. These parameters are highly site specific and can only be determined with sufficient accuracy by measurements at a particular site over a sufficient long period [6]. The Weibull distribution has been extensively used to describe the frequency distribution of wind speeds for the purpose of evaluating the wind energy [7].

Alsaad worked on wind energy potential in selected areas in Jordan. The study reveals that the total rated wind power that can be generated from the four selected wind farms is $136 \mathrm{MW}$ while the expected total energy that can be produced from the four selected wind farms is $18.9 * 10^{3} \mathrm{GWh}$ [8].

Ojosu presented a statistical analysis of wind energy potential for power generation in Nigeria, 15 years (1968- 
1983) monthly average wind speed data was used for six sites at four distinctive regions in Nigeria using Weibull distribution. The analysis shows that wind turbine can generate up to $97 \mathrm{MWh} /$ year [9].

Zeljko assessed wind energy resource in the south Banat region, Serbia. His assessment revealed that south Banat possesses good wind energy potential and have a promising region for development of the project for wind farms [10].
In this study, wind power density in four locations in north eastern (Bauchi and Maiduguri) and western (Kano and Sokoto) regions of Nigeria were analyzed using wind speed data at $10 \mathrm{~m}$ height collected from Nigerian meteorological station NIMET Abuja for the period of (2000-2016). These locations are characterized by different geographical and climatologically conditions as shown in Table 1 below;

Table 1. Geographical data for the selected locations.

\begin{tabular}{llllll}
\hline LOCATIONS & STATE & LAT (N) & LONG (E) & ALT (M) & ALT (FT) \\
\hline Bauchi & Bauchi & $10^{\circ} 18^{\prime} 57$ & $9^{\circ} 50^{\prime} 39$ & 615 & 2020 \\
\hline
\end{tabular}

Maiduguri Borno $11^{\circ} 50^{\prime} 4713^{\circ} 9^{\prime} 37299984$

Kano Kano $11^{\circ} 59^{\prime} 478^{\circ} 31^{\prime} 04761564$

Sokoto Sokoto $13^{\circ} 3^{\prime} 55^{\circ} 13^{\prime} 45272895$

Source: http://www.fallingrain.com

\section{Distributional Parametres of the Wind Speed Data}

In the present study, monthly wind speed data in the northern region of Nigeria for the years $(2000-2016)$ have been statistically analysed. The wind speed data were recorded at a height of $10 \mathrm{~m}$ by a cup generator anemometer at Nigeria Meteorological Agency (NIMET). The continuously recorded wind speed values and the standard deviations calculated for the available monthly wind speed data using equations below [11];

$$
\begin{gathered}
v_{m}=\frac{1}{N}\left[\sum_{i=1}^{N} v_{i}\right] \\
\sigma=\left[\frac{1}{N-1} \sum_{i=1}^{N}\left(v_{i}-v_{m}\right)^{2}\right] 1 / 2
\end{gathered}
$$

\subsection{Weibull Distribution Model}

Determination of the Weibull probability density function and cumulative function requires the knowledge of two parameters: $k$ and $c$ (shape and scale factors), respectively. Both of these parameters are function of and $v_{m}$. The Weibull probability density function and the cumulative distribution function is given by [12];

$$
\begin{gathered}
f_{w}(v)=\left(\frac{K}{c}\right)\left(\frac{K}{c}\right)^{K-1} \exp \left[-\left(\frac{v}{c}\right)^{k}\right] \\
F_{W}(v)=1-\exp (v / c)^{k}
\end{gathered}
$$

The Weibull parameters (scale and shape factors) can be calculated analytically from the available wind speed data using the relations below $[13,14]$;

$$
\begin{gathered}
c=\left[\frac{k^{2.6674}}{0.184+\left(0.816^{k 2.73859}\right)}\right] \\
k=\left[\frac{\sigma}{v}\right]^{-1.090}
\end{gathered}
$$

\subsection{Rayleigh Distribution Model}

This is the simplest velocity probability distribution to represent the wind resource since it requires only knowledge of the mean wind speed $\left(v_{m}\right)$. The probability density function and the cumulative distribution functions of the Rayleigh model are given by $[15,16]$;

$$
\begin{gathered}
f_{R}(v)=\frac{\pi}{2} \frac{v}{v^{2} m} \exp \left[-\left(\frac{\pi}{4}\right)\left(\frac{v}{v^{2} m}\right)^{k}\right] \\
F_{R}(v)=1-\exp \left[-\left(\frac{\pi}{4}\right)\left(\frac{v}{v_{m}}\right)^{2}\right]
\end{gathered}
$$

where $f_{W}$ is Weibull probability density function, $F_{W}$ is the Weibull cumulative distribution function, $f_{R}$ is the Rayleigh probability density function, $F_{R}$ is Rayleigh cumulative distribution function, $c$ is the scale factor $(\mathrm{m} / \mathrm{s})$ and $k$ is the shape factor (dimensionless).

\section{Analysis of Wind Speed Data}

The wind speed probability distribution is in time series usually arranged in the frequency distribution format. The available time series data were translated into frequency distribution format, as shown in Tables 2-5 for Bauchi, Maiduguri, Kano and Sokoto. The wind speed is grouped into classes (bins) as given in the second column of Tables 25. The mean wind speeds were calculated for each speed intervals (third column). The fourth column gives the frequency of occurrence of each speed class. The probability density distribution is presented in fifth column. The probability density function for Weibull and Rayleigh are presented in sixth and seventh column, the cumulative distribution function for both Rayleigh and Weibull are present in eighth and ninth column. 
Table 2. Arrangement of the measured monthly series data in frequency distribution for Bauchi in month of January.

\begin{tabular}{lllllllll}
\hline $\mathbf{J}$ & $\mathbf{V j}$ & $\mathbf{V m j}$ & $\mathbf{f j}$ & $\mathbf{F ~ ( v j )}$ & $\mathbf{F w}(\mathbf{v j})$ & $\mathbf{f R}(\mathbf{v j})$ & $\mathbf{F R}(\mathbf{v})$ \\
\hline 1 & $0-0.9$ & 0.45 & 0 & 0.000 & $5.45262 \mathrm{E}-05$ & $2.12698 \mathrm{E}-09$ & 1 \\
2 & $1-1.9$ & 1.45 & 2 & 0.118 & 0.076813476 & 0.199965388 & 0.889869 \\
3 & $2-2.9$ & 2.45 & 14 & 0.824 & 1.017947398 & 0.293669502 & 0.538248 \\
4 & $3-3.9$ & 3.45 & 1 & 0.059 & 0.005020743 & 0.217221871 & 0.322734 \\
5 & $4-4.9$ & 4.45 & 0 & 0.000 & $6.33475 \mathrm{E}-21$ & 0.152524121 & 0.208819 \\
6 & $5-5.9$ & 5.45 & 0 & 0.000 & $1.23105 \mathrm{E}-93$ & 0.10994378 & 0.144576 \\
7 & $6-6.9$ & 6.45 & 0 & 0.000 & 0.000 & 0.082081098 & 0.1055 \\
8 & $7-7.9$ & 7.45 & 0 & 0.000 & 0.000 & 0.063266859 & 0.080173 \\
9 & $8-8.9$ & 8.45 & 0 & 0.000 & 0.000 & 0.05010226 & 0.062895 \\
10 & $9-9.9$ & 9.45 & 0 & 0.000 & 0.000 & 0.040584663 & 0.050613 \\
11 & $10-10.9$ & 10.45 & 0 & 0.000 & 0.000 & 0.03350453 & 0.041585 \\
12 & $11-11.9$ & 11.45 & 0 & 0.000 & 0.000 & 0.028106483 & 0.034761 \\
13 & $12-12.9$ & 12.45 & 0 & 0.000 & 0.000 & 0.023902753 & 0.029481 \\
14 & $13-13.9$ & 13.45 & 0 & 0.000 & 0.000 & 0.020568503 & 1 \\
15 & $14-14.9$ & 14.45 & 0 & 0.000 & 0.000 & 1 & 1 \\
\hline
\end{tabular}

Table 3. Arrangement of the measured monthly series data in frequency distribution for Maiduguri in month of January.

\begin{tabular}{|c|c|c|c|c|c|c|c|c|}
\hline $\mathbf{J}$ & $\mathbf{V j}$ & Vmj & $\mathbf{f j}$ & $F(\mathbf{v j})$ & Fw (vj) & fR (vj) & FR (v) & Fw (v) \\
\hline 1 & $0-0.9$ & 0.45 & 0 & 0.000 & 0.000322647 & $2.96724 \mathrm{E}-40$ & 1 & $3.53269 \mathrm{E}-05$ \\
\hline 2 & $1-1.9$ & 1.45 & 0 & 0.000 & 0.012224344 & 0.000405129 & 0.99989 & 0.004322078 \\
\hline 3 & $2-2.9$ & 2.45 & 2 & 0.118 & 1.060438779 & 0.053045476 & 0.958972 & 0.036710202 \\
\hline 4 & $3-3.9$ & 3.45 & 2 & 0.118 & 0.156153464 & 0.130266217 & 0.800213 & 0.141615161 \\
\hline 5 & $4-4.9$ & 4.45 & 4 & 0.235 & 0.259939661 & 0.148861193 & 0.620162 & 0.35252841 \\
\hline 6 & $5-5.9$ & 5.45 & 5 & 0.294 & 0.277428349 & 0.137034712 & 0.47553 & 0.632120559 \\
\hline 7 & $6-6.9$ & 6.45 & 4 & 0.235 & 0.172604487 & 0.117672632 & 0.3692 & 0.864459472 \\
\hline 9 & $8-8.9$ & 8.45 & 0 & 0.000 & 0.006855186 & 0.083099253 & 0.235447 & 0.997675965 \\
\hline 10 & $9-9.9$ & 9.45 & 0 & 0.000 & 0.000281867 & 0.07011598 & 0.193178 & 0.99932516 \\
\hline 11 & $10-10.9$ & 10.45 & 0 & 0.000 & 2.82214E-06 & 0.059626046 & 0.160993 & 0.999999506 \\
\hline 12 & $11-11.9$ & 11.45 & 0 & 0.000 & $5.00308 \mathrm{E}-09$ & 0.051143707 & 0.136027 & 0.999999999 \\
\hline 13 & $12-12.9$ & 12.45 & 0 & 0.000 & 1.09929E-12 & 0.044244124 & 0.116328 & 1 \\
\hline 14 & $13-13.9$ & 13.45 & 0 & 0.000 & $2.01753 \mathrm{E}-17$ & 0.038586846 & 0.100542 & 1 \\
\hline 15 & $14-14.9$ & 14.45 & 0 & 0.000 & $2.00676 \mathrm{E}-23$ & 0.033907613 & 0.087117 & 1 \\
\hline
\end{tabular}

Table 4. Arrangement of the measured monthly series data in frequency distribution for Kano in month of January.

\begin{tabular}{|c|c|c|c|c|c|c|c|c|}
\hline $\mathbf{J}$ & $\mathbf{V j}$ & Vmj & $\mathbf{f j}$ & $F(v j)$ & Fw (vj) & fR (vj) & FR (v) & Fw (v) \\
\hline 1 & $0-0.9$ & 0.45 & 0 & 0.000 & $6.4049 \mathrm{E}-08$ & $4.9119 \mathrm{E}-135$ & 1 & 4.60419E-09 \\
\hline 2 & $1-1.9$ & 1.45 & 0 & 0.000 & $3.01585 \mathrm{E}-05$ & $5.1742 \mathrm{E}-13$ & 1 & $6.98563 \mathrm{E}-06$ \\
\hline 3 & $2-2.9$ & 2.45 & 0 & 0.000 & 0.000475938 & $6.00314 \mathrm{E}-05$ & 0.999974486 & 0.000186287 \\
\hline 4 & $3-3.9$ & 3.45 & 0 & 0.000 & 0.002876447 & 0.005726742 & 0.995177349 & 0.001586522 \\
\hline 5 & $4-4.9$ & 4.45 & 0 & 0.000 & 0.010904314 & 0.02890183 & 0.959476263 & 0.007781827 \\
\hline 6 & $5-5.9$ & 5.45 & 0 & 0.000 & 0.031045179 & 0.05609319 & 0.882031172 & 0.027407208 \\
\hline 7 & $6-6.9$ & 6.45 & 2 & 0.118 & 0.07149146 & 0.073806714 & 0.782590046 & 0.076679353 \\
\hline 8 & $7-7.9$ & 7.45 & 2 & 0.118 & 0.135751977 & 0.81072571 & 0.681396447 & 0.178539571 \\
\hline 9 & $8-8.9$ & 8.45 & 3 & 0.176 & 0.207957003 & 0.081299872 & 0.588975791 & 0.351231526 \\
\hline 10 & $9-9.9$ & 9.45 & 7 & 0.412 & 0.241501352 & 0.077684965 & 0.508792810 & 0.581658710 \\
\hline 11 & $10-10.9$ & 10.45 & 1 & 0.059 & 0.190889234 & 0.072315089 & 0.44085348 & 0.80518956 \\
\hline 12 & $11-11.9$ & 11.45 & 0 & 0.000 & 0.087328167 & 0.06637814 & 0.383830531 & 0.944891326 \\
\hline 13 & $12-12.9$ & 12.45 & 2 & 0.118 & 0.018411491 & 0.060495588 & 0.336063525 & 0.992520361 \\
\hline 14 & $13-13.9$ & 13.45 & 0 & 0.000 & 0.00131585 & 0.054964739 & 0.295967254 & 0.999643951 \\
\hline 15 & $14-14.9$ & 14.45 & 0 & 0.000 & $2.1328 \mathrm{E}-05$ & 0.04990655 & 0.262168211 & 0.999996042 \\
\hline
\end{tabular}

Table 5. Arrangement of the measured monthly series data in frequency distribution for Sokoto in month of January.

\begin{tabular}{|c|c|c|c|c|c|c|c|c|}
\hline $\mathbf{J}$ & $\mathbf{V j}$ & $\mathbf{V m j}$ & $\mathbf{f j}$ & $F(v j)$ & Fw (vj) & fR (vj) & FR (v) & Fw (v) \\
\hline 1 & $0-0.9$ & 0.45 & 0 & 0.000 & $1.18186 \mathrm{E}-08$ & $1.7584 \mathrm{E}-106$ & 1 & $7.43829 \mathrm{E}-10$ \\
\hline 2 & $1-1.9$ & 1.45 & 0 & 0.000 & $1.5766 \mathrm{E}-05$ & $2.61636 \mathrm{E}-10$ & 1 & $3.19731 \mathrm{E}-06$ \\
\hline 3 & $2-2.9$ & 2.45 & 0 & 0.000 & 0.000396846 & 0.000492249 & 0.999765 & 0.000135991 \\
\hline 4 & $3-3.9$ & 3.45 & 0 & 0.000 & 0.003252479 & 0.0156008443 & 0.985200 & 0.001570612 \\
\hline 5 & $4-4.9$ & 4.45 & 1 & 0.059 & 0.015435157 & 0.050376437 & 0.920526 & 0.009653239 \\
\hline 6 & $5-5.9$ & 5.45 & 0 & 0.000 & 0.052023539 & 0.078111584 & 0.815164 & 0.004851170 \\
\hline 7 & $6-6.9$ & 6.45 & 1 & 0.059 & 0.133119443 & 0.090389517 & 0.700419 & 0.128756485 \\
\hline 8 & $7-7.9$ & 7.45 & 5 & 0.294 & 0.251944128 & 0.091627580 & 0.594850 & 0.320431131 \\
\hline 9 & 8- 8.9 & 8.45 & 6 & 0.353 & 0.310891146 & 0.087096752 & 0.504558 & 0.613517435 \\
\hline
\end{tabular}




\begin{tabular}{lllllllll}
\hline $\mathbf{J}$ & $\mathbf{V j}$ & $\mathbf{V m j}$ & $\mathbf{f j}$ & $\mathbf{F ~ ( v j )}$ & $\mathbf{F w}(\mathbf{v j})$ & $\mathbf{f R}(\mathbf{v j})$ & $\mathbf{F R}(\mathbf{v})$ & Fw (v) \\
\hline 10 & $9-9.9$ & 9.45 & 3 & 0.176 & 0.193026768 & 0.080165626 & 0.429667 & 0.879384748 \\
11 & $10-10.9$ & 10.45 & 1 & 0.059 & 0.038653482 & 0.072606160 & 0.368215 & 0.986988908 \\
12 & $11-11.9$ & 11.45 & 0 & 0.000 & 0.001237289 & 0.065312359 & 0.317845 & 0.999762585 \\
13 & $12-12.9$ & 12.45 & 0 & 0.000 & $2.21353 \mathrm{E}-06$ & 0.058597804 & 0.276402 & 0.999999746 \\
14 & $13-13.9$ & 13.45 & 0 & 0.000 & $4.87309 \mathrm{E}-11$ & 0.052588578 & 0.242098 & 1 \\
15 & $14-14.9$ & 14.45 & 0 & 0.000 & $1.59534 \mathrm{E}-18$ & 0.047280961 & 0.213499 & 1 \\
\hline
\end{tabular}

\subsection{Wind Power Density}

The knowledge of the wind characteristics and evaluation of the power in wind is very important for an assessment of wind power project. The wind power depends on the air density, the cube of the wind speed and the wind speed frequency distribution. Therefore, this parameter is generally considered a better indicator of the wind resource than wind speed. The mean wind power density is proportional to the mean cube of the wind speed, $v^{3}$ and can be estimated by using the following equation [2].

$$
P=\frac{1}{2} \rho v^{3}
$$

where $\rho=$ is air density, usually taken as $1.225 \mathrm{~kg} / \mathrm{m}^{3}$.

\subsection{Error in Calculating Power Density}

The errors in calculating the power densities using the models in comparison to those using the measured probability density distribution can be obtained using the following formula [5].

$$
\text { Error }(\%)=\frac{P_{w, R}-P_{m, R}}{P_{m, R}}
$$

The yearly average error in calculating power densities using both Weibull and Rayleigh functions is obtained by using equation below [5].

$$
\text { Error }(\%)=\frac{1}{12} \sum_{i=1}^{12}\left(\frac{P_{W, R}-P_{m, R}}{P_{m, R}}\right)
$$

\section{Results and Discussion}

From the results obtained, Table 6 presents Weibull distribution parameters for northwest and northeast Nigeria and from the Table it can be seen that Rayleigh models returns higher percentage error in all the four locations considered in the study. It can also be observed from the Table that Kano, Sokoto and Maiduguri corresponds to wind class II, since it has power density above $100 \mathrm{~W} / \mathrm{m}^{2}$, this particular site is ideal for grid - connected applications while Bauchi corresponds to wind class I, since it has power density less than $100 \mathrm{~W} / \mathrm{m}^{2}$. Therefore, this particular site is not ideal for grid - connected applications, which may be adequate for non-connected electrical and mechanical applications, such as battery charging and water pumping.

Comparing of probability density functions according to the observed data with Weibull and Rayleigh models for the investigated sites as illustrated in Figures 1-4 below. It can be seen from Figures 1 and 2 that Bauchi and Maiduguri shows peak values of 1.01795 and 1.06044 for Weibull while values for Rayleigh are 0.29367 and 0.14886 respectively. It can also be seen from Figures 3 and 4 that Sokoto and Kano shows peak values 0.24150 and 0.31089 for Weibull while values for Rayleigh are 0.81073 and 0.09162 respectively.

Table 6. Weibull distribution parameters for northwest (Kano \& Sokoto) and northeast (Bauchi \& Maiduguri) Nigeria.

\begin{tabular}{lllllll}
\hline Locations & k & c & v (m/s) & Pmr & Weibull (\%) & Rayleigh (\%) \\
\hline Kano & 6.71 & 9.35 & 7.69 & 8.74 & 538.89 & 61.29 \\
Sokoto & 6.02 & 2.58 & 7.41 & 274.12 & 65.33 \\
Bauchi & 4.71 & 5.90 & 2.36 & 11.02 & 30.95 \\
Maiduguri & 5.47 & 5.45 & 120.49 & 28.04 & 36.23 \\
\hline
\end{tabular}

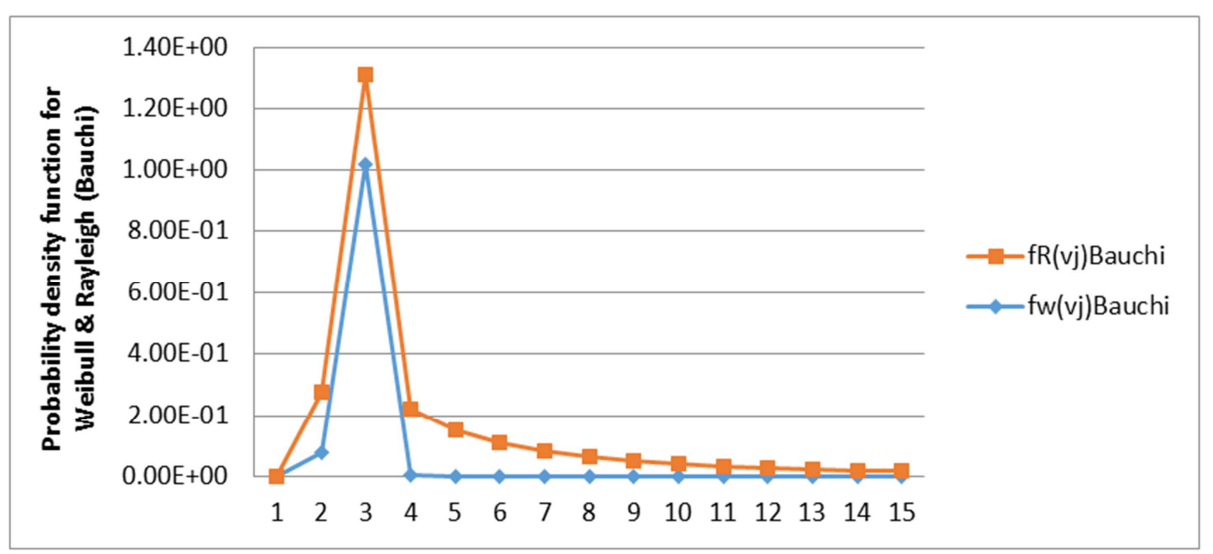

Figure 1. Comparison of Weibull and Rayleigh probability density function for Bauchi. 


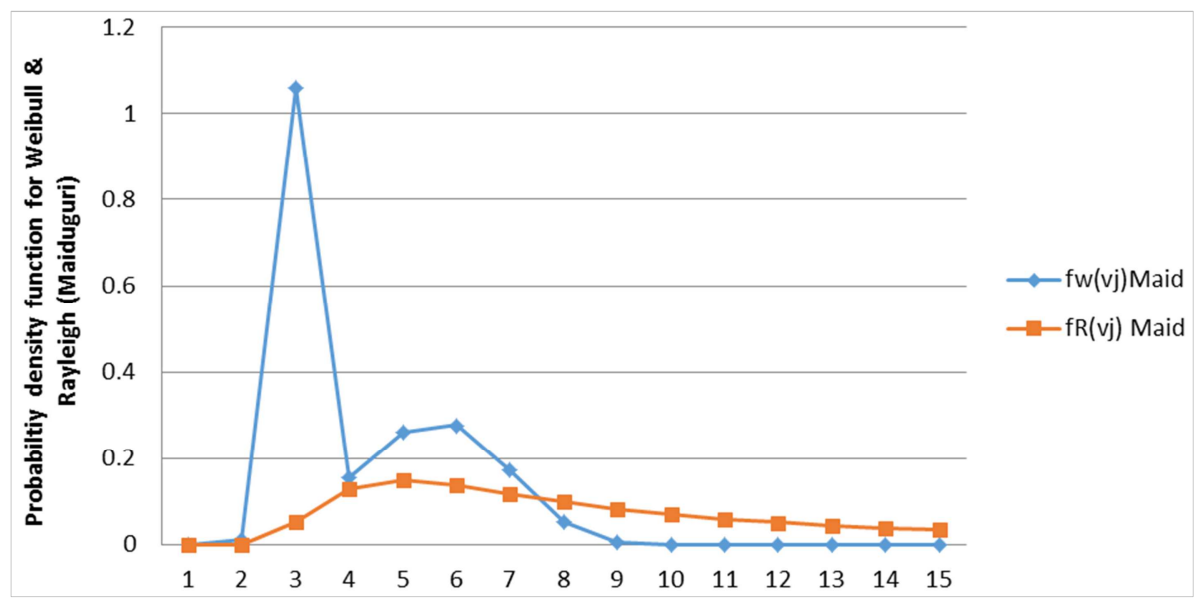

Figure 2. Comparison of Weibull and Rayleigh probability density function for Maiduguri.

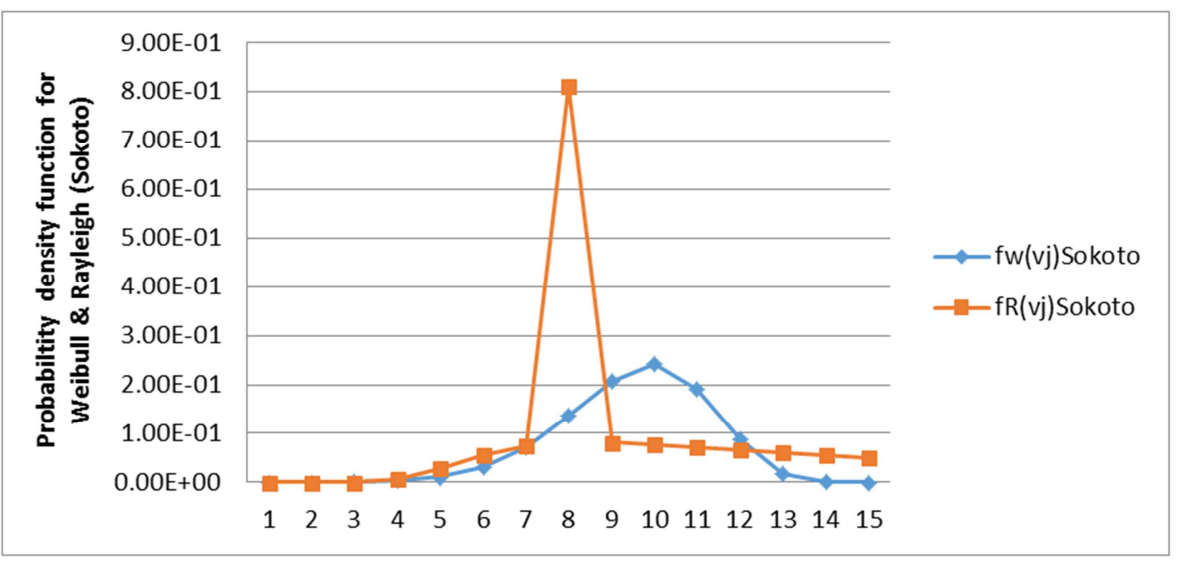

Figure 3. Comparison of Weibull and Rayleigh probability density function for Sokoto.

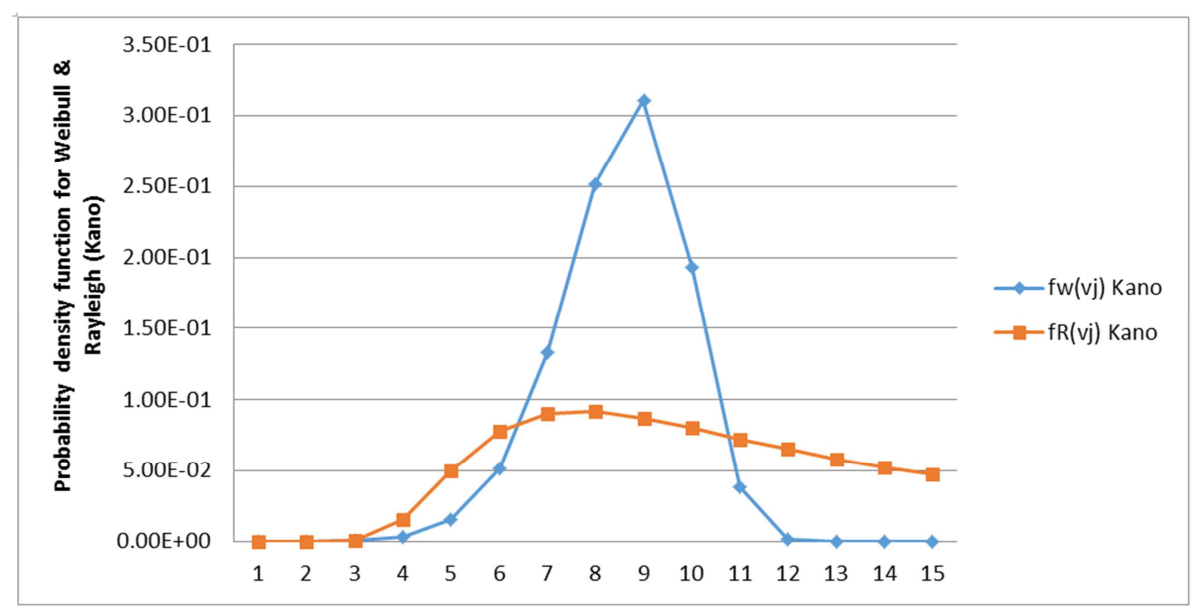

Figure 4. Comparison of Weibull and Rayleigh probability density function for Kano.

\section{Conclusion}

In this study, Weibull distribution parameters for northwest (Kano \& Sokoto) and northeast (Bauchi \& Maiduguri) Nigeria and distribution arrangement of the measured monthly series data in frequency distribution for all the locations were evaluated. It was observed that the Weibull model returns higher error as compared to the Rayleigh model, this show that the Weibull model is best fit in the locations considered in the study.

From the results obtained, it was also found that Kano, Sokoto in the northwest region have values of wind power density of $538.89 \mathrm{~W} / \mathrm{m}^{2}$ and $274.12 \mathrm{~W} / \mathrm{m}^{2}$ respectively and Maiduguri northeast region have value of $120.49 \mathrm{~W} / \mathrm{m}^{2}$, these locations corresponds to wind class II, since the wind power density are above $100 \mathrm{~W} / \mathrm{m}^{2}$, which are quite viable for electricity generation. Bauchi northeast was found to have 
wind power density of $11.02 \mathrm{~W} / \mathrm{m}^{2}$, this location corresponds to wind class I, since the wind power density is less than $100 \mathrm{~W} / \mathrm{m}^{2}$, which is best applicable for battery charging and water pumping.

Finally, it can be concluded that, the northwest region is quite viable for wind power plants because it has the highest wind power density as compared to northeast region.

\section{References}

[1] Ahmed, S. A. S. and Hanitseh, R. (2006). Evaluation of wind energy potential and electricity generation on the coast of Mediterranean sea in Egypt. Renewable Energy, 31: 11831202.

[2] Hossain, J., Shina, V. and Kishore V. V. N (2011). A GIS based assessment of potential wind farms in India. Renewable Energy, 36: 3257-67.

[3] Diaf, S. and Notton, G. (2013). Evaluation of electricity generation and energy cost of wind energy conversion system in Southern Algeria. Renewable and Sustainable Energy Reviews, 23: 379-390.

[4] Ahmed, A. (2016). An assessment of wind power density in south east Nigeria, Enugu. American Journal of Modern Energy. 6: 1-5.

[5] Proma, A. K., Pobitra, K. H. and Sabbir, R. (2014). Wind energy potential estimation for different region of Bangladesh. International Journal of Renewable and Sustainable Energy, 3: 47-52.

[6] Ucar, A. and Balo, F. (2008). Investigation of wind characteristics and assessment of wind generation potentiality in Uludag - Bursa, Turkey Applied Energy, 86: 333-339.

[7] Schmid, J and Palz, W. (1896). European wind energy technology, state of the art of wind energy converts in the
European community, series. Volume 3, published by D. Radel publishing company.

[8] Alsaad, M. A. (2013). Wind energy potential in selected areas in Jordan. Energy Conversion and Management, 65: 704-708.

[9] Ojosu, J. O. and Salawu, R. I. (1989). A statistical analysis of wind energy potential for power generation in Nigeria. Nigeria Journal of Solar Energy, 8: 273-288.

[10] Zeljko. D. And Jovan. M. (2012). Assessment of wind energy resource in the south Banat region of Serbia. Renewable and Sustainable Energy, 16: 3014-3023.

[11] Akpinar, E. K. and Akpinar, S. (2004). Statistical analysis of wind energy potential on the basis of the Weibull and Rayleigh distributions for Agin-Elazig, Turkey. Power and Energy. 218: 557-565.

[12] Celik, A. N. (2003). Assessing the suitability of wind speed probability distribution functions based on the wind power density. Renewable Energy, 28: 1563-1574.

[13] Chen, K., Song, M. X. and Zhang, X. (2013). A statistical method to merge wind cases for wind power assessment of wind farm. Journal of Wind Engineering and Industrial Aerodynamics, 119: 69-77.

[14] Mostafaeipour, A., Sedaghat, A., Dehgann-Niri, A. A., and Kalantar, V. (2011). Wind energy feasibility study for city of Sharbabak in Iran. Renewable and Sustainable Energy Review, 15: 2545-2456.

[15] Feregh, G. M., Darwish A. S. K. and Sayigh, A. A. M. (1990). Wind energy potential for Bharain. Proceedings of the first World Renewable Energy Congress, United Kingdom, 2: 156159.

[16] Ahmed, A. (2018). Estimation of wind energy potential for two locations in north-east region of Nigeria. International Journal of Advance Trends in Engineering, Science and Technology, 5: 6-10. 